\title{
Stroke Rehabilitation: Which is the Main Functional Outcome to Reach?
}

Loredana Cavalli*, Andrea Guazzini, Bruno Rossi and Carmelo Chisari

University of Florence, Italy

\begin{abstract}
Background: Stroke rehabilitation targets range from treatment of spasticity to pain reduction, gait speed gain, or autonomy amelioration. A correct evaluation of individual residual capabilities is essential to select the most appropriate rehabilitative programme; furthermore the observation of rehabilitative outcomes can provide information about gait training effects and possible compensation mechanisms.
\end{abstract}

Aim: To investigate the main outcome to reach in stroke rehabilitation.

Methods: We examined retrospectively a heterogeneous sample of 119 subjects recovered for the treatment of stroke outcomes. Functional parameters were assessed before and after rehabilitative treatment, such as upper limbs motility impairment, lower limb sensitiveness, muscle trophism or tone, necessity of auxilium, Berg and Fugl-Meyer scale.

Results: A consistent improvement of standing equilibrium was reported, regardless of gender, stroke nature, hemiparetic side, type of rehabilitation performed, botulin toxin use and initial conditions, with an average increase of Berg and Fugl-Meyer scales score of $14 \%$ and $21 \%$, respectively. The variation of equilibrium and motility across treatment resulted directly proportional and negatively correlated to lower limbs sensitivity impairment. On the contrary, initial equilibrium resulted inversely correlated with the variation of motility and vice versa. Interestingly, older subjects seem to better increase equilibrium and sensitivity as measured by Fugl-Meyer scale.

Conclusion: In stroke subjects any type of rehabilitation leads to a consistent improvement of standing balance. While proportional to motility and sensitivity increase, this result is inversely correlated to initial motility score, suggesting that an appropriate evaluation of the stroke patient's functional parameters at admission contributes to select the main rehabilitation targets and the best therapeutic strategy.

Keywords: Stroke; Rehabilitation; Equilibrium; Motility; Age; Ischemic stroke

\section{Introduction}

Stroke is the major cause of disability worldwide, with an important social-economic impact [1]. One stroke on four is fatal and between 25 to $50 \%$ of the survivors requires a rehabilitative treatment [2]. According to the Copenhagen Stroke Study, 14\% of survivors walk with assistance, while $22 \%$ are unable to ambulate [3], resulting in impairment in daily living [4].

Stroke rehabilitation is complex, long lasting and expensive and its functional outcome is influenced not only by brain lesion site and extension, but also by medical, demographic and neuropsycologic factors [1]. Age, for example, was reported as inversely proportional to amount of recovery [5]; similarly, disability at admission, measurable as Barthel Index (BI), is a powerful predictor of functional final outcome [1], as well as comorbidity. A further variable showing a relevant relationship with later outcome is the onset-to-admission interval (OAI), as rehabilitation beginning within 60 days after the stroke onset has been recognized to obtain better results compared to delay one [1].

The functions most frequently compromised by stroke are muscle strength, power, balance and gait [6], often associated with spasticity [7-9]. Muscle hypostenia, reduction in range of motion, abnormal muscle tone and loss of sensory and motor coordination contribute to difficulties of postural control in stroke patients [10], thus increasing the risk of falls, with a relevant socio-economic burden [11].

Therefore, recovering trunk control and balance is one of the main targets of rehabilitation for patients with stroke.

\section{Materials and Methods}

A retrospective analysis of records related to post-acute phase stroked patients was reported. Once excluded patients with disorders of consciousness, or with consistent comorbidity influencing the final outcome, such as severe respiratory or cardiovascular insufficiency, recent femoral fracture, general debility associated mental illness, or severe anemia, a total of 119 subjects admitted in Neuro-Rehabilitation Unit of Cisanello Hospital in Pisa, Italy, between 2009 and 2013 were included. Clinical characteristics detected by the physiatrist at the entrance in hospital were reported as distinct discrete parameters, including hemiparetic side, functional impairment of the affected upper limb, spasticity and hypotrophy of the lower limb, compromised tactile and proprioceptive sensitivity of lower limbs. The gait ability before rehabilitation was indicated with a score rising from 0 to 7 on the basis of the necessity of increasingly important walking aids. For each patient, the rehabilitative program was indicated, both for upper limbs (conventional physiotherapy, isokinetic dynamometer or no treatment) and for lower limbs (Lokomat, tapis roulant and conventional physiotherapy), as well as botulin toxin employment for the treatment of spasticity. The rehabilitative project outcome was reported as a clinical improvement in the control of the trunk, in the standing posture and in the gait pattern.

Moreover, standing balance was evalued by Berg scale, while Fugl-Meyer (FM) scale was performed to assess motility, equilibrium, sensitivity, articolarity and pain, before and after the treatment (Table $1)$. Of the whole sample, only thirty subjects performed gait tests and data about six min walking (6MWT), ten-meters (10MWT), time to get

${ }^{*}$ Corresponding author: Loredana Cavalli, M.D., PhD, University of Florence, Italy, Tel: +393471715805; E-mail: cavallil.doc@gmail.com

Received October 18, 2017; Accepted October 26, 2017; Published October 31, 2017

Citation: Cavalli L, Guazzini A, Rossi B, Chisari C (2017) Stroke Rehabilitation Which is the Main Functional Outcome to Reach? Int J Neurorehabilitation 4: 293. doi: 10.4172/2376-0281.1000293

Copyright: @ 2017 Cavalli L, et al. This is an open-access article distributed under the terms of the Creative Commons Attribution License, which permits unrestricted use, distribution, and reproduction in any medium, provided the original author and source are credited. 
correlation analysis was carried out in order to investigate relations among clinical and quantitative parameters; then, a Monte Carlo Bootstrap method was applied for each variable in order to extract subsamples of comparable size, followed by the execution of the $t$ test or of the ANOVA test.

\section{Results}

The patients, 64 males (54\%) and 55 females (46\%), had an average age of 66.8 years $( \pm 11.7)$, ranging from 36 to 87 years. Stroke resulted of ischemic origin in 73 subjects and hemorrhagic in 46 with hemiparesis regarding right body side in 53 subjects, left in 58 or bilateral in 8 patients. The mean stay duration in rehabilitation was 55 days $( \pm 30.1)$, ranging from 10 to 90 days.

Functional conditions at the access in hospital, such as upper limb functional impairment, lower limb spasticity and muscle hypotrophy,

\begin{tabular}{|c|c|c|c|c|}
\hline $\begin{array}{l}\text { Functional } \\
\text { scales and } \\
\text { tests }\end{array}$ & $\begin{array}{c}T_{0} \text { average } \\
\text { score (before } \\
\text { rehab) } \pm S D\end{array}$ & $\begin{array}{l}T_{1} \text { average } \\
\text { score (after } \\
\text { rehab) } \pm S D\end{array}$ & $\begin{array}{c}\text { Average single } \\
\text { patient } T_{0}-T_{1} \\
\text { variation }( \pm S D)\end{array}$ & $\begin{array}{c}\text { Average } \\
\text { percent single } \\
\text { patient } T_{0}-T_{1} \\
\text { variation }\end{array}$ \\
\hline Berg & $29 / 56 \pm 16.2$ & $38 / 56 \pm 13.6$ & $\begin{array}{c}7.94( \pm \\
11.98) / 56\end{array}$ & $+14 \%$ \\
\hline FM mobility & $36 / 98 \pm 24.8$ & $50 / 98 \pm 30.0$ & $14.4( \pm 19.2)$ & $+14.7 \%$ \\
\hline FM equilibrium & $6 / 24 \pm 3.9$ & $18 / 24 \pm 2.8$ & $2.5( \pm 22.8)$ & $+20.8 \%$ \\
\hline FM sensitivity & $15 / 24 \pm 7.6$ & $19 / 24 \pm 5.6$ & $3.4( \pm 5.8)$ & $+14.1 \%$ \\
\hline FM articolarity & $38 / 44 \pm 6.5$ & $40 / 44 \pm 5.2$ & $1.6( \pm 4.0)$ & $+3.6 \%$ \\
\hline FM pain & $38 / 44 \pm 6.1$ & $40 / 44 \pm 5.1$ & $1.51( \pm 5.7)$ & $+3.4 \%$ \\
\hline $\begin{array}{l}10 \mathrm{~m} \text { walking } \\
\text { test_time (s) }\end{array}$ & $54.8^{\prime \prime} \pm 39.9$ & $45.4 " \pm 35.0$ & $-5.83 "( \pm 23.7)$ & $-17.5 \%$ \\
\hline $\begin{array}{l}10 \mathrm{~m} \text { walking } \\
\text { test_speed } \\
(\mathrm{m} / \mathrm{s})\end{array}$ & $\begin{array}{c}0.29 \mathrm{~m} / \mathrm{sec} \pm \\
0.23\end{array}$ & $\begin{array}{c}0.36 \mathrm{~m} / \mathrm{sec} \pm \\
0.24\end{array}$ & $0.05( \pm 0.17)$ & $+24.3 \%$ \\
\hline $\begin{array}{l}6 \text { min walking } \\
\text { test distance } \\
(\mathrm{m})\end{array}$ & $\begin{array}{c}102.8 \mathrm{mt} \pm \\
79.9\end{array}$ & $132.7 \mathrm{mt} \pm 88.8$ & $18.98( \pm 51.03)$ & +29.1 \\
\hline TUG (s) & $55.7 " \pm 35.6$ & $47.5 " \pm 34.7$ & $-3.47 "( \pm 11.98)$ & $-14.7 \%$ \\
\hline
\end{tabular}

FM: Fugl-Meyer; TUG: Test Up and Go

Table 1: Clinimetric evaluation assessed before and after rehabilitation by means of Berg scale, Fugl-Meyer scale (F-M), $10 \mathrm{~m}$ walking test, 6 min walking test and test-up-and-go (TUG).

2A: Significant Pearson correlations between age, hospitalization, auxilium and the other parameters.

\begin{tabular}{|c|c|c|c|}
\hline & Age & $\begin{array}{l}\text { Rehabilitation } \\
\text { duration (days) }\end{array}$ & $\begin{array}{l}\text { Necessary } \\
\text { auxilium at the } \\
\text { entrance }\end{array}$ \\
\hline Age & 1 & & 0.406 * \\
\hline $\begin{array}{l}\text { Auxilium required at the } \\
\text { entrance }\end{array}$ & 0.406 * & & \\
\hline Berg $T_{0}$ & $-0.288^{* *}$ & & -0.657 * \\
\hline Berg $T_{1}$ & & & -0.438 * \\
\hline FM motility $T_{0}$ & & $-0.255^{* *}$ & $-0.290 * *$ \\
\hline FM motility $T_{1}$ & & -0.316 * & \\
\hline FM equilibrium $T_{0}$ & -0.426 * & & -0.629 * \\
\hline$F M$ equilibrium $T_{1}$ & -0.378 * & & -0.455 * \\
\hline FM sensitivity $T_{0}$ & -0.226 ** & & -0.282 ** \\
\hline$F M$ pain $T_{0}$ & & & $-.244 * *$ \\
\hline 10-MWT T & 0.440 ** & & 0.532 ** \\
\hline Speed $T_{0}$ & & & -0.764 * \\
\hline Speed $T_{1}$ & -0.494 ** & & \\
\hline 6-MWT $T_{0}$ & & & -0.739 * \\
\hline TUG $T_{0}$ & 0.609 ** & & 0.404 ** \\
\hline
\end{tabular}

*: $p$ value $<0.001 ;{ }^{* *}: p$ value $<0.05$
2B: Correlations between FM scores and other parameters.

\begin{tabular}{|c|c|c|c|c|}
\hline & $\begin{array}{c}\text { Delta FM } \\
\text { motility }\end{array}$ & $\begin{array}{c}\text { Delta FM } \\
\text { equilibrium }\end{array}$ & $\begin{array}{l}\text { Delta FM } \\
\text { sensitivity }\end{array}$ & $\begin{array}{c}\text { Delta FM } \\
\text { articolarity }\end{array}$ \\
\hline Age & & $0.194^{* *}$ & $0.215^{* *}$ & \\
\hline Auxilium required & $0.276^{* *}$ & 0.399 * & & \\
\hline Berg $_{0}$ & $-0.409 * *$ & $-0.319 * *$ & & \\
\hline FM motility $T_{0}$ & & -0.292 ** & & \\
\hline FM motility $T_{1}$ & 0.569 * & & & \\
\hline FM equilibrium $T_{0}$ & $-0.345^{*}$ & -0.676 * & -0.416 * & \\
\hline FM sensitivity $T_{0}$ & -0.266 ** & -0.429 * & -0.679 * & \\
\hline FM articolarity $T_{0}$ & & & & -0.604 * \\
\hline FM articolarity $T_{1}$ & $0.305^{* *}$ & $0.235^{* *}$ & & \\
\hline FM pain $T_{0}$ & & & & -0.326 * \\
\hline FM pain $T_{1}$ & $0.213^{* *}$ & & & \\
\hline 6-MWY $\mathrm{T}_{1}$ & $0.515^{* *}$ & & & \\
\hline Delta FM motility & 1 & 0.641 * & 0.444 * & 0.230 ** \\
\hline $\begin{array}{l}\text { Delta FM } \\
\text { equilibrium }\end{array}$ & $0.641^{*}$ & 1 & 0.646 * & \\
\hline $\begin{array}{l}\text { Delta FM } \\
\text { sensitivity }\end{array}$ & 0.444 * & 0.646 * & 1 & \\
\hline
\end{tabular}

*: $p$ value $<0.001 ;{ }^{* *}$ : $p$ value $<0.05$

2C: Berg scores correlations.

\begin{tabular}{|c|c|c|c|}
\hline & Berg $T_{0}$ & Berg $T_{1}$ & Delta Berg \\
\hline Age & $-0.288^{* *}$ & & \\
\hline Necessary auxilium & $-0.657^{*}$ & $-0.438^{*}$ & $0.388^{* *}$ \\
\hline FM motility $T_{0}$ & $0.326^{\star \star}$ & & \\
\hline FM equilibrium $T_{0}$ & $0.615^{\star}$ & $0.355^{\star \star}$ & -0.4 ** \\
\hline FM equilibrium $T_{1}$ & $0.580^{*}$ & $0.687^{*}$ & \\
\hline FM sensitivity $T_{0}$ & $0.325^{\star *}$ & & \\
\hline FM sensitivity $T_{1}$ & & $0.317^{* *}$ & \\
\hline FM pain $T_{0}$ & 0.322 ** & & \\
\hline 10-MWT T & & $-0.565^{* *}$ & \\
\hline 10-MWT T & & -0.570 ** & \\
\hline Speed $T_{0}$ & 0.788 * & $0.587^{* *}$ & \\
\hline Speed $T_{1}$ & $0.652^{*}$ & 0.769 * & \\
\hline 6-MWT T. & $0.743^{*}$ & $0.591 * *$ & \\
\hline 6-MWT $\mathrm{T}_{1}$ & & 0.704 * & \\
\hline TUG T & & $-0.727^{*}$ & \\
\hline TUG $T_{1}$ & & $-0.637^{*}$ & \\
\hline Delta FM motility & $-0.409^{* *}$ & & $0.642^{*}$ \\
\hline Delta FM equilibrium & $-0.319^{* *}$ & & $0.465^{*}$ \\
\hline Delta FM sensitivity & & & $0.341^{* *}$ \\
\hline
\end{tabular}

Table 2: Statistically significant correlations between the functional parameters analyzed: A) Correlations between age, hospitalization, auxilium and the other parameters; B) Correlations between FM scores and other parameters; C) Berg scores correlations.

tactile and/or proprioceptive sensitivity compromised in lower limbs and deambulation ability, are summarized in Figures $1 \mathrm{~A}$ and $1 \mathrm{~B}$, rehabilitation strategies in Figure 1C.

The results of FM scale, performed in 104 subjects and Berg scale, assessed in 50 patients, before and after rehabilitative treatment are reported in Table 1, as well as 6MWT, TUG, 10MWT performed in 30 subjects. Statistically significant Pearson correlations among variables $(\mathrm{p}<0.05)$ are reported in Table $2 \mathrm{~A}$.

Equilibrium assessed by Berg and FM scales score results more impaired in oldest subjects, who require more important auxilia for walking, as well as tactile and proprioceptive sensitivity of lower limbs, which correlates with need of auxilia. 

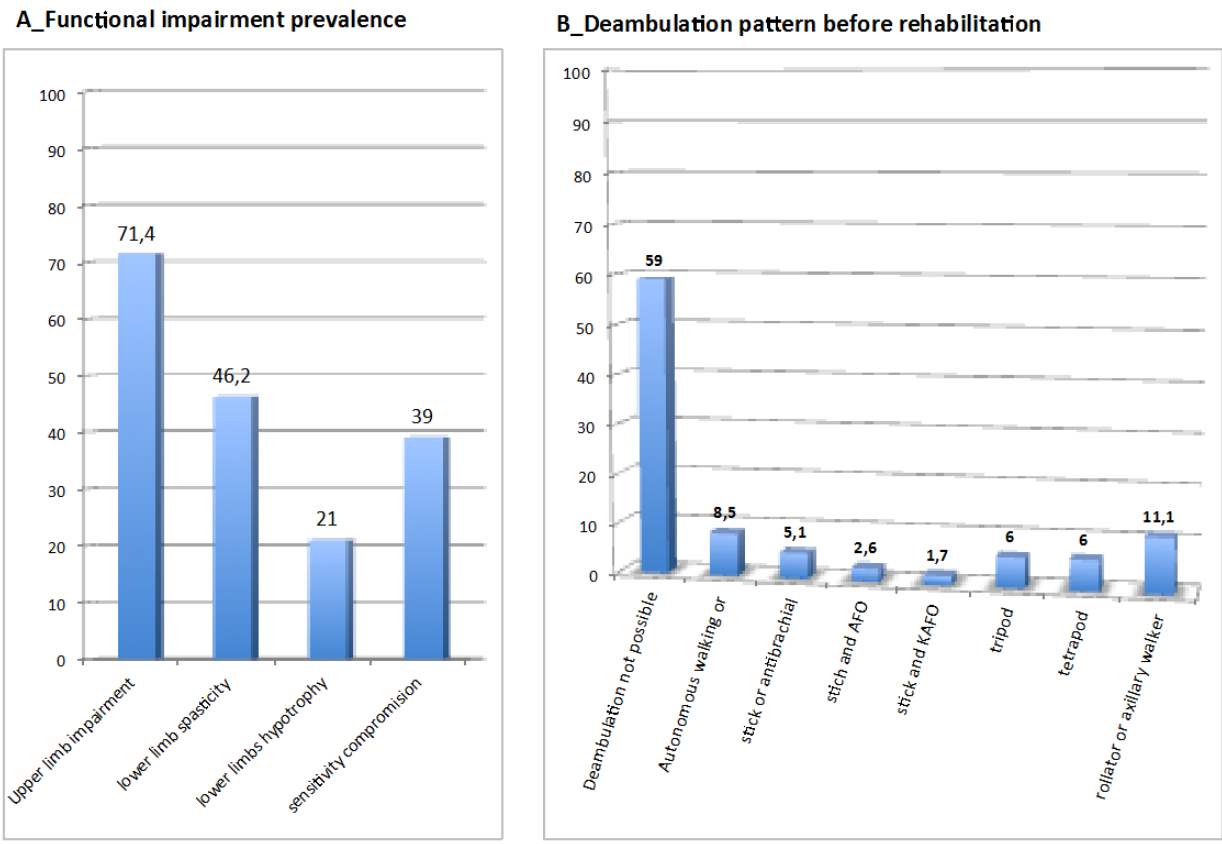

C_Rehabilitation strategies for lower and upper limbs applied in our sample.

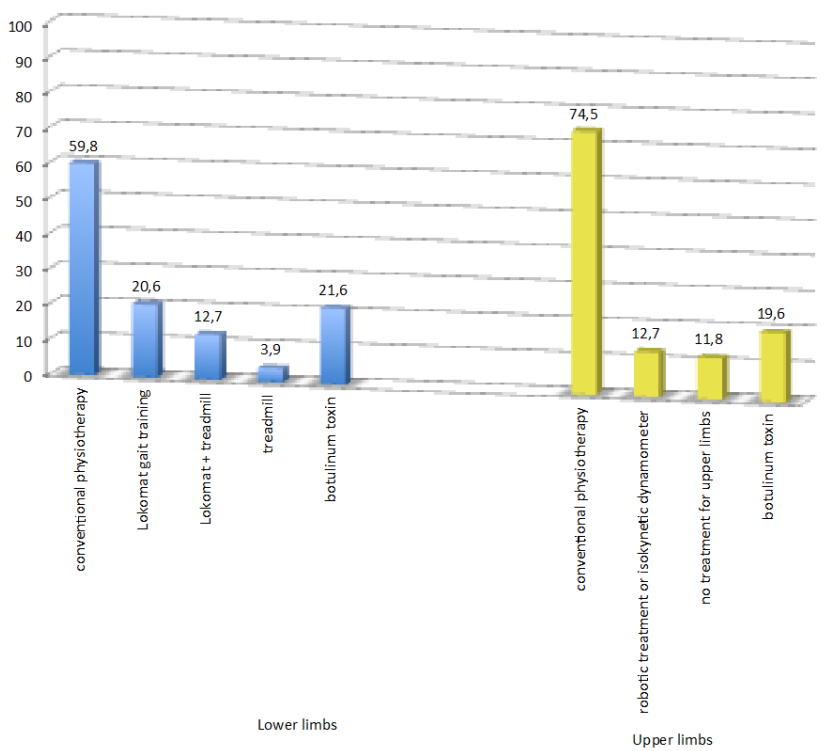

Figure 1: Functional baseline parameters and rehabilitation strategies.

Gait test reveals a significant influence of age, with older subjects employing longer time to walk for ten meters and to get up and go and with a lower speed at the end of treatment. Auxilia necessity results proportional to gait test impairment.

Further correlations have been evalued, between each parameter examined and the average "deltas", i.e., the single-patients variations of FM, Berg scale, gait test during rehabilitation treatment, as well as correlations between the deltas, each to the other (Table 2B).

Interestingly, older subjects seem to better increase equilibrium and sensitivity, while decreasing speed at gait test.
A positive correlation exists between the initial gait impairment, valued on the basis of the auxilium used and the improvement in motility and equilibrium at FM scale.

Initial equilibrium results inversely correlated with the variation of motility across treatment, as well as initial motility score is inversely proportional to equilibrium delta.

Sensitivity impairment at lower limbs is associated with lower motility and equilibrium variation. These latter parameters appear to be reciprocally proportional to final articolarity and the increase of articolarity across treatment is closely related to initial pain and vice versa. 
Regarding gait test, final performance at 6MWT positively correlates to motility variation, proportional to equilibrium, sensitivity, articolarity deltas and to the amelioration in the other gait tests. The progress in speed across treatment correlates to the amelioration in $6 \mathrm{MWT}$, as well as happens for TUG and 10MWT.

Interestingly, variation of Berg score is positively correlated to variation of motility and sensitivity. When related to gait test, final Berg score correlates to $\mathrm{T}_{0}$ and $\mathrm{T}_{1}$ speed and $6 \mathrm{MWT}$, but it is inversely proportional to $\mathrm{T}_{0}$ and $\mathrm{T}_{1} \mathrm{TUG}$ and 10MWT, as shown in Table $2 \mathrm{C}$.

\section{Discussion}

Neurorehabilitation is a method for relearning a task by compensatory strategies or by adaptively recruiting alternative pathway [12].

Post-acute one is the phase during which most of functional recovery can be obtained, where several prognostic factors may influence the global outcome. Advanced age often represents a unfavorable factor as potentially associated with comorbidity and fragility [2]; the presence of apraxia, aphasia or dysarthria, dysphagia and malnutrition, neglect, depression or anxiety represents a further obstacle to recovery [2]; the neurological lesion severity is a determinant predictor of patient's impairment, as well as timeliness, intensity and duration of rehabilitation have been shown to have a significant impact on ADL potential recovery [13].

Although there is no generally accepted method for rehabilitating stroke survivors, several studies support the choice of task-oriented training [13], where the recovery of movement, organized around a goal and constrained by the environment, is allowed not only by restoration from impairments but also by experience-dependent reorganization patterns in both the damaged and the contralateral hemisphere [13].

In this paper, the clinical and functional evaluation of a heterogeneous sample of 119 subjects hospitalized for stroke rehabilitation was examined, in order to figure out which weight was represented by each parameter in determining the final outcome.

Walking ability was considered as one of the main functional index, as influenced by balance, joint articolarity, muscle tone and strength, coordination. Therefore, deambulation at the entrance and at the end of the treatment was quantified in a 0 to 7 score scale, as the need of an increasingly assistant auxilium, from the absence of device or the only use of an ankle-foot-orthosis (AFO) represented by a 0 score, to the need of an antibrachial (score $=1$ ), or a stick with an AFO (2), or with a Knee-AFO (3), to the use of a tripod (4), a tetrapod (5), a rollator (6), or the inability to walk (7).

A Pearson correlation was established between gait impairment and all the other parameters examined, i.e. patient's sex and age, stroke type, lesion side, rehabilitative treatment duration, upper limb motility reduction, lower limb sensitiveness alteration, muscle hypotrophy or hypertonia, Berg and FM scale.

The tactile sensorial impairment at lower limbs, regarding $65.5 \%$ of the whole sample, resulting from the neurological examination and by FM scale, was more frequent in patients with hemorragic stroke and left hemiparesis and its recovery resulting by FM scale (delta FM sensitivity) was shown to correlate with a balance improvement (delta Berg), as reported in Table 2.

According to literature, old age resulted correlated to a worst gait ability score, as well as a low balance score measured by Berg and FM scales, both before $\left(\mathrm{T}_{0}\right)$ and after treatment $\left(\mathrm{T}_{1}\right)$. The resting parameters did not affect walking performance in a significant manner.

In our sample, undergone a retrospective study, the rehabilitation protocol was selected on the basis of individual needs and clinical characteristics, so that a comparison among different therapeutic approaches was not possible.

What emerged as consistent across all the patients was that the main gait impairment index is represented by initial balance (expressed by Berg and/or FM equilibrium score), which is inversely correlated with initial motility and vice versa $(\mathrm{p}<0.05$, Table $2 \mathrm{~B})$. Interestingly, the balance improvement (delta FM equilibrium) appears as directly proportional to motility increase (delta FM motility) and vice versa $(\mathrm{p}<0.05$, Table $2 \mathrm{~B})$.

\section{Conclusion}

The most appropriate strategy should be selected, as early as possible, on the basis of the functional parameters that each subject presents at the entrance in hospital, in order to reach the best motor performances allowing the major quality recovery of daily life. Our data suggest that balance recovery could be considered the main target of stroke rehabilitation.

\section{Conflict of Interest}

The authors declare that they have no competing interests. We certify that no party having a direct interest in the results of the research supporting this article has or will confer a benefit on us or on any organization with which we are associated.

\section{Author's Contribution}

Loredana Cavalli collected data in a database and drafted the main text. Andrea Guazzini made the statistical analysis. Bruno Rossi critically reviewed the whole paper adding his contribute. Carmelo Chisari planned the project and coordinated the work. All the authors reviewed and approved the final paper.

\section{References}

1. Paolucci S, Antonucci G, Grasso MG, Morelli D, Troisi E, et al. (2000) Early versus delayed inpatient stroke rehabilitation: A matched comparison conducted in Italy. Arch Phys Med Rehabil 81: 695-700.

2. Paolucci S, Morelli D (2012) Stroke: Riabilitazione. Compendio d Neuroriabilitazione, Verducci Editore.

3. Jorgensen HS, Nakayama H, Raaschou HO, Olsen TS (1995) Recovery of walking function in stroke patients: The Copenhagen Stroke Study. Arch Phys Med Rehabil 76: 27-32

4. Dobkin BH (2005) Clinical practice. Rehabilitation after stroke. N Eng J Med 352: $1677-1684$.

5. Nakayama H, Jorgensen HS, Raaschou HO, Olsen TS (1994) The influence of age on stroke outcome. The Copenhagen Stroke Study. Stroke 25: 808-813.

6. Stavric VA, McNair PJ (2012) Optimizing muscle power after stroke: A crosssectional study. J Neuroeng Rehabil 9: 67

7. Lundstrom E, Smits A, Terent A, Borg J (2010) Time-course and determinants of spasticity during the first six months following first-ever stroke. J Rehabil Med 42: 296-301.

8. Sommerfeld DK, Gripenstedt U, Welmer AK (2012) Spasticity after stroke: An overview of prevalence, test instruments and treatments. Am J Phys Med Rehabil 91: 814-820.

9. Fernandez-Gonzalo R, Nissemark C, Åslund B, Tesch PA, Sojka P (2014) Chronic stroke patients show early and robust improvements in muscle and functional performance in response to eccentric-overload flywheel resistance training: A pilot study. J Neuroeng Rehabil 11: 150.

10. Allum JH, Bloem BR, Carpenter MG, Hulliger M, Hadders-Algra M (1998) Proprioceptive control of posture: A review of new concepts. Gait Posture 8: 214-242.

11. SPREAD_Stroke Prevention and Educational Awareness Diffusion (2017) Ictus cerebrale: Linee guida italiane di prevenzione e trattamento. 
Citation: Cavalli L, Guazzini A, Rossi B, Chisari C (2017) Stroke Rehabilitation: Which is the Main Functional Outcome to Reach? Int J Neurorehabilitation 4: 293. doi: 10.4172/2376-0281.1000293

12. Matthews PM, Johansen-Berg $H$, Reddy $H$ (2004) Non-invasive mapping of brain functions and brain recovery: Applying lessons from cognitive neuroscience to neurorehabilitation. Restor Neurol Neurosci 22: 245-260.
13. Rensink M, Schuurmans M, Lindeman E, Hafsteindòttir T (2009) Task-oriented training in rehabilitation after stroke: Systematic review. J Adv Nurs 65: 737 754 